\title{
nature
}

\section{Not everything is in the genes}

Last week's reports of a possible genetic basis to an individual's ability to handle complex social situations highlights the importance of developing frameworks to ensure that genetic information is used responsibly.

"W hy boys will be boys." "Girls may inherit intuition gene from father." The newspaper headlines that accompanied last week's report about research by David Skuse and his colleagues at the Institute of Child Health in London, suggesting a strong, sex-dependent genetic component in reactions to certain types of social situations, had a certain predictability (see Nature 387, 705; 1997). The explicit message that these headlines, and the articles that accompanied them, conveyed was dramatic, describing how the research appears to have produced a clear example of the way in which modern genetics may provide us with useful tools for understanding social behaviour.

Skuse studied a group of 80 girls with Turner's syndrome, characterized by possessing only one X chromosome (females usually have a pair). Some had inherited their single X chromosome from their father and some from their mother, and the study found that the parental origin of the X chromosome was closely correlated with an individual girl's ability to cope with social situations. Similar differences were found between boys - who have a single X chromosome inherited from their mother — and girls. Skuse's conclusion, widely quoted in the press reports, was that his results show a clear genetic basis for the difference in social skills between women and men.

These results are scientifically stimulating. But it is important to remain wary of over-interpretation. For there is an inevitable temptation to use them to justify a form of genetic determinism which despite our awareness of the history of eugenics movements and other misuses of genetics in the past - remains a powerful force in modern society. Reporting the hunt for, or discovery of, a 'gene for' homosexuality, violence, alcoholism or mental illness has become a regular feature of newspaper science. Each time it happens, there are scientists quick to point out how the characteristics described are frequently the result of a complex interaction between genetic susceptibility and environmental stimulus. But there are a few others, more provocatively quotable, who are equally quick to use such 'discoveries' to support claims of the extent to which the straitjacket of nature remains impervious to the coaxing of nurture.

The very successes of genetics research can, often unwittingly, appear to strengthen the latter arguments, and thus the social policies that appear to flow logically from them. The myth of biological utopia reached its nadir in the eugenic policies of Nazi Germany. Few believe the crude myth any longer. But, in more sophisticated forms, it remains a powerful influence on certain trends of modern political and social thought. Of course, where there is solid and credible evidence of a biological basis to certain aspects of social behaviour, it would be foolish to ignore the implications. Knowledge of such biological roots, for example, could play an important role in helping individuals to cope with difficult social situations more effectively.

The danger, however, is that the biological or genetic explanation becomes the dominant measure of 'normality', and that other more subtle influences on behaviour are denied their legitimate role. Perhaps this danger is most acute in the study of mental illness, where sufferers from diseases found to have a strong genetic component risk being labelled as socially 'subnormal'. But similar threats exist for anyone who comes to be recognized as 'genetically disabled' - with the implication that society has little chance of improving their plight.

Ironically, the new insights into social behaviour provided by modern genetics make it more, not less, important that we learn to imbue our use of these insights with a basic commitment to human rights. The proposed universal declaration on the human genome being drawn up by the United Nations Educational, Scientific and Cultural Organization is a timely step towards modernizing legislation in this field, both nationally and internationally. Modern genetics has provided one of the most vivid illustrations of Francis Bacon's maxim that "knowledge is power". We share a common responsibility to use that knowledge for the benefit of all.

\section{A lesson on preparedness}

\section{Guidelines for handling allegations of scientific fraud are essential to preserve the reputation of science.}

G ermany has been caught off guard. The emergence of a scientific fraud case of substantial proportions (see page 750) has exposed the fact that few research institutions have formal guidelines for dealing with allegations of scientific misconduct. As a result, Germany's scientific community has had to respond in an ad hoc way to the new case, involving two researchers, now at different universities, who stand accused of fabricating results when they worked together at a research institute in Berlin.

So far, the investigation into the allegations appears to have been carried out in an exemplary fashion. Committees of inquiry were rapidly set up at all three institutions, and their conclusions were put to a common committee of experts last week. The deans of the two universities and the director of the Berlin research centre have discussed their investigations openly. Both universities have been in close contact with their respective regional ministries of education, which are responsible for hiring or firing university faculty members.
Perhaps it has needed a case like this one to rouse German academics from their traditional complacency in regarding fraud as something to be handled discreetly by the research departments concerned. Indeed, many leading academics have argued in the past that scientific fraud could never become a significant problem in Germany, where the struggle for research grants is much less vicious than in the United States. The few lonely voices which have been calling for guidelines to be prepared - in case of need - are now finding keener ears.

The outcome of this unprecedented case will help to define what can be done within the constraints of Germany's legal system. A US-style central office of scientific integrity is not a solution in a country whose research funding organizations prize their independence from the state. But the heads of Germany's research organizations and its rectors' conference should at least agree on a common set of guidelines adaptable to individual needs. Such guidelines would protect not only the integ-rity of German science, but also its reputation with the taxpayer. 